\title{
Nanotechnology: Review on Emerging Techniques in Remediating Water and Soil Pollutions
}

\author{
*1YARIMA, A; ${ }^{2}$ ALI, R; ${ }^{1}$ ABDULLAHI, AA; ${ }^{1}$ IDRIS, Z \\ ${ }^{*}$ Department of Plant Science, Bio-resource Development Center Michika, National Biotechnology Development Agency, Abuja, Nigeria \\ ${ }^{2}$ Zoology Department, Modibbo Adama University of Technology, Yola, Nigeria \\ *Corresponding Author Email: adamuyerima08@gmail.com; Tel: +2347067907982
}

\begin{abstract}
Environmental Pollution is becoming a global challenge in both developing and the developed countries, pollutants discharge from oil and gas industries and or agricultural practices continue effecting the health of human and other animal in an ecosystem in one way or the other. This necessitated the development of a techniques to clean up of the polluted environment. Remediation of pollutants relies mainly on using various techniques like physical, chemical and or biological methods for the removal of contaminants from different environmental media be it soil, water, and or air. These techniques have their own limitations as the toxicity of the degrading agents, time consuming and the fate of the environment after remediation matters a lot. Therefore, nanotechnology is gaining interest in remediating pollutions as nanoparticles are relatively cost effective, sensitive and selective and can be used as sensors to monitor toxins, organic contaminants and heavy metals in land, water and or air. The enhanced properties and effectiveness of nanotechnology-based materials makes them suitable for nano remediation. This review provides an overview of the nanomaterials: Organic based nanomaterials (Dendrimers), inorganic (TiO2, nZVI), carbon-based (Carbon nanotubes, (CNTs)), and composite-based materials) used in environmental remediation. These nanomaterials were reported to remediate different contaminants in the environment such as heavy metals, pathogens, pesticides, dyes, chlorinated organic compounds, and polycyclic aromatic hydrocarbons.
\end{abstract}

DOI: https://dx.doi.org/10.4314/jasem.v24i5.31

Copyright: Copyright $(\subseteq 2020$ Yarima et al. This is an open access article distributed under the Creative Commons Attribution License (CCL), which permits unrestricted use, distribution, and reproduction in any medium, provided the original work is properly cited.

Dates: Received: 10 March 2020; Revised: 29 April 2020; Accepted: 28 May 2020

Keywords: Nanotechnology, nanoparticles, Nano remediation, pollutions and environments.

Environmental pollution raises concern in the past years due to increase in human activities on oil and gas industries, agricultural practices, industrialization and many more. These activities are the primary source of contaminations in water, air and land and as such have drawn major concern globally. Environmental pollution is one of the main challenges today's societies are facing, the risks associated with these pollutions may not be immediate, but do accumulate over time, posing harmful effects to the inhabitants (Neely et al., 1974). Water and soil pollutions are among the most serious forms of pollution that pose long-term damage to the environment, and the pollutants include petroleum products (Yunus et al., 2012; Nnaji, 2017), pathogens (Kang et al., 2007; Cortes et al., 2009), heavy metals (Gao et al., 2009, Rizwan et al., 2014) and organic pollutants such as pnitrophenol (Rizwan et al., 2014). These pollutants are usually laden with toxic contaminants that are deleterious to global health as they caused problems like neurological and mental disorder, organ dysfunction, cancer, and even death to some extents (WHO, 2013), diseases of the heart and cancer of the lung (Yunus et al., 2012), dysfunction of kidney, reproductive system, liver, brain and central nervous system (Chen and Lim, 2002). Hence the need for immediate response to curb the effects of such pollutants, this necessitates the development of ecofriendly approach and bioremediation come to play. Bioremediation is a process that involves in cleaning up of pollutants from environment using microorganisms (Nkereuwem et al., 2010), it is relatively ecofriendly and cost effective compares to chemical and physical methods of removing pollutions (Chibueze et al., 2016). This eco-friendly remediation approach gained interest as it reduces contaminants accumulations in the environments to the lowest level, hence minimizes the global environmental impacts induced by greenhouse gas emissions (Reddy and Adams, 2010). The ultimate goal of bioremediation is to effectively restore the polluted environments in an eco-friendly approaches and at a considerable low cost. However, bio remediation approach has its own limitations in combating pollutants concentration in an environment, that include time consuming, and some time poisoning the organisms used (Rickerby and 
Morrison, 2007; Tripathi, et al., 2018). This raises concerns again, hence the need to develop more efficient and cost effective approaches for remediating environmental pollutions. Nanotechnology is becoming an option in environmental remediation technology using various nanoparticles (Mueller and Nowack, 2010; Olyaie and Banejad, 2012; Pandey et al., 2015; Guerra et al., 2018; Tripathi et al., 2018 and Isa et al., 2019). Nanotechnology may be defines as understanding and controlling matter at dimensions between approximately 1- 100 nanometers, where unique phenomena enable novel applications (USEPA, 2011), it is a new technique in environmental remediation and termed as nanoremediation (Machado et al., 2013), this technique has definitely identified as early as possible new areas of science and technology that have the potential to impact strongly on environment. When the environmental cleanup involves using nanoparticles or nanomaterials formed from living organism is termed as nano bioremediation (Yadav et al., 2017). It has been used in remediating water and soil pollutants (Bottero et al., 2006; Olyaie and Banejad, 2012) and has proven to be a new an effective strategy for cleaning up residual pollutants in a variety of environment into eco-friendly manner. The advantages of nanotechnology in environmental remediation include sensing, detecting, preventing and remediating pollutions (Durán, 2008), low cost, less time consuming and efficient (Li et al., 2008), the fate of the environment after remediation and the toxicity of the degrading agent used (Olyaie and Banejad et al., 2014) are need to be considered and as such, nanoparticles are nontoxic (Li et al., 2008), and can diminishes pollution production (Watlington, 2005), hence are relatively safe to handle, this may help to reduce the impact of pollutions on an environments. Nano remediation is more sensitive and selective than conventional methods and can be used as sensors to monitor toxins, organic contaminants and heavy metals in land, water and air environments (Khin et al., 2012). The goal standard of this review is to provide a comprehensive overview of some of the methods employed in nanotechnology in remediating environmental (water and soil) pollutions.

Why Nanoparticles over bulk particles? Research in nano sciences reported that many of the environmental challenges after remediation are usually being resolved using nonabsorbent, nanocatalysts, bioactive nanoparticles, nanopowder, nanotubes, magnetic nanoparticles, and nanoparticles (Mamadou and Savage, 2005; Savage and Diallo, 2005). Nanotechnology has several advantages that helps to improve the existing remediation techniques (Yunus et al., 2012) and this creates new method that is better than the current ones, this is possible due to the high surface area to-volume ratio of the nanoparticles which enable them to absorb maximum amount of pollutants, and their extremely small size also allow quantum effects to come to play (Hochella and Madden, 2005) and this make them accessible to contaminants hence prioritized in-situ over ex-situ form of remediation (Pandey et al., 2016). Nanoparticles are more reactive than the bulk ones because of their increase surface area per unit mass (Rickerby and Morrison, 2007; Isa et al., 2019). Nano science has being used in a variety of applications within the scientific, environmental, industrial, and medical arenas (USEPA, 2011).

Nano particles strategies in combatting pollutions: Nanotechnologies are expected to make a great contributions in curbing the effects of pollutions in an ecosystem using nano particles and nanomaterials, they are known to be incorporated into various materials to improve different properties (NRP, 2017). Controlling pollutions from their source of origin or limiting the process to a certain areas is a promising step, thus, the strategies employed by nanoparticles in controlling pollutions include: (1) Some nano particles like zero valent ions act as reducing agent by donating electrons to contaminants, this reduces them to a less toxic substances (Chuang et al., 1995; Mueller and Nowack, 2010) then the insoluble substances would be precipitated (Helal et al., 2016). (2) Nanoparticles may be engineered with specificity and affinity to a particular contaminants this helps to uptake the pollutants without subsequent release (Olyaie and Banejad, 2012). (3) Nanomaterials like dendrimers have interior voids which enable them to trap small substances (Zimmerman and Lawless, 2001; Triano et al., 2015). (4) Little amount of energy can be used to degrade organic and inorganic contaminates (Nowack, 2008; Isa et al., 2019). (5) Some nanoparticles interfere with DNA synthesis thereby destroying the bacterial cell wall (Thai et al., 2010; Raj Kumar and Gopinath, 2017). (6) Prevent the formation of harmful intermediate and by products as well as preventing the release of contaminants at manufacturing sites (Pandey et al., 2016).

Applications of nanotechnology in remediating water and soil pollutions using different nanoparticles: Nanoparticle (NPs) are classified into four different groups (USEPA, 2007; Jeevanandam et al., 2018) they include: Carbon-based nanomaterials, Inorganicbased nanomaterials, Composite-based nanomaterials and Organic-based nanomaterials.

Carbon-based nanomaterials: Carbon based nanomaterials composes mostly of carbon and are in 
various shape. They are classified based on their shape and geometrical structures and include; nanohorns (horn-shaped) carbon nanotube (CNT) (tube-shaped), carbon nanospheres (fullerenes) (ellipsoidal spherical shape), and zero-dimension dots exhibited quantum character as carbon quantum dots (CQDs) (Khare et al., 2019). They are macromolecules consisting of sheets of carbon atoms covalently bonded in hexagonal lattices (Niu and Cai, 2012) and are being incorporated into various materials to improve different properties (NRP, 2017).

Carbon nanotubes (CNTs): Carbon nanotubes (CNTs) are among the types of allotrope of carbon-based nanomaterials that have excellent electrical and mechanical properties (Khare et al., 2019). CNT and nanocrystals have been reported by Kang et al., 2007; Cortes et al., 2009 Rizwan et al., 2014 and Isa et al., 2019 to have wide range of environmental applications such as those used as sorbent, antimicrobial and environmental sensors in remediating pollutants. They emerged in the field of nanotechnology due to their nanosize structure and novel properties. Attaching to a functional group, unique adsorption properties (Mansoori et al., 2008), mesoporous structure and large surface area to volume ratio enable them to be used in adsorption of pollutants from drinking water (Savage and Diallo, 2005). Yu et al., 2014 also

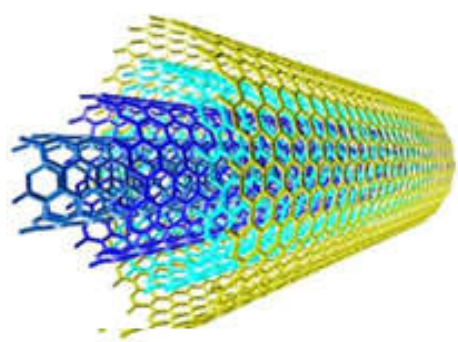

Figure 1 reported that hydrogen bonding, $\pi-\pi$ interactions, hydrophobic effect, electrostatic interactions and covalent bonding are the mechanisms employed by CNT to adsorb organic compounds. They were reported to remediate various contaminants including soil toxic organic compounds (polychlorinated biphenyls and polycyclic aromatic hydrocarbons (Pan and Xing, 2010), organic and inorganic contaminants (Jin et al., 2007) and Pathogenic microorganisms from waste water by depth-filtration mechanism (Mostafavi et al., 2009). Two types of CNTs were reported namely: Single-Walled Carbon Nanotubes (SWCNTs) and Multi-walled Carbon Nanotubes (MWCNTs) (Chen et al., 2015; Raj Kumar and Gopinath, 2017). Both SWCNTs and MWCNTs are unique macromolecules with thermal stability, one dimensional structure and special chemical properties (Firozjaee et al., 2017). SWCNTs possesses antimicrobial properties which destroys the bacterial cell wall by interfering with metabolic reactions and or inhibit the DNA synthesis (Thai et al., 2010; Raj Kumar and Gopinath, 2017) it also effectively adsorb the PCBs by reducing its bioavailability from sediment (Hua et al., 2017). MWCNTs also has both antimicrobial and adsorption ability to remediate heavy metals (Raj Kumar and Gopinath, 2017; Correia, et al., 2019), thereby reducing the risk of contaminants in soil (Josko et al., 2013).

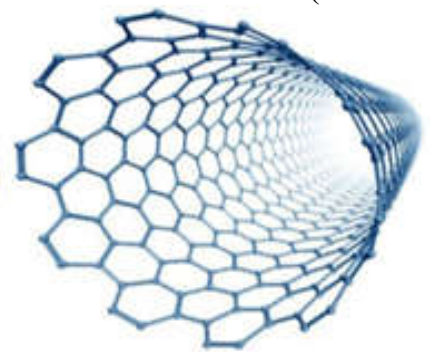

Figure 2

Fig 1. Represent Multi-walled Carbon Nanotubes (MWCNTs), while Fig 2 Represent Single-walled Carbon Nanotubes (SWCNTs) (Source: Rafique et al., 2016)

Inorganic-based nanomaterials: These are nanomaterials that include metal and metal oxide nanoparticles and nanomaterials (Jeevanandam et al., 2018). While metal nanoparticles include $\mathrm{Pt}, \mathrm{Rh}, \mathrm{Pd}$, Ir, $\mathrm{Ag}, \mathrm{Au}, \mathrm{Cu}, \mathrm{Co}, \mathrm{Ni}, \mathrm{FeNi}, \mathrm{Cu}_{3} \mathrm{Au}, \mathrm{CoNi}, \mathrm{CdTe}$, $\mathrm{CdSe}$, and $\mathrm{ZnS}$ (Rizwan et al., 2014), metal oxide nanoparticles are $\mathrm{ZnO}, \mathrm{Fe}_{2} \mathrm{O}_{3}, \mathrm{Fe} 3 \mathrm{O} 4, \mathrm{MgO}, \mathrm{BaCO}_{3}$, BaSO4, and $\mathrm{TiO}_{2}$ (Rizwan et al., 2014) and semiconductors such as silicon and ceramics (Jeevanandam et al., 2018).

$\mathrm{TiO}_{2}$ Nanoparticles: Nanoparticles have unique properties compare to their bulk counterpart, such properties include high reactivity attributed to their increase surface area per unit mass, wider reactivity i.e. attacking both organic and inorganic molecules and large surface area to volume ratio which allows quantum effect to come to play (Isa et al., 2019). These novel properties warrant them to be the most suitable for remediating environmental pollutions. $\mathrm{TiO}_{2}$ has been frequently investigated metal-based nanoparticles for remediating environmental pollution with nontoxicity, low-cost, photo catalytic and energy converting properties ( $\mathrm{Li}$ et al., 2008), $\mathrm{TiO}_{2}$ were reported to purifies water (Adesina, 2004; Kabra et al., 2004 and Obare and Meyer, 2004; Li et al., 2008), remediate $\mathrm{Cr}$ (VI), Ag (I), Pt (II), chlorinated alkanes, benzenes, dioxins and furans and polychlorinated biphenyls etc (Savage and Diallo, 2005), pesticides, dyes, toxic compounds from the waste water 
(Meghmala et al., 2019) and act as antioxidant, antibacterial and cytotoxicity activity against $\mathrm{Mg} 63$ osteosarcoma cell lines (Chatterjee et al., 2016), extraction of heavy metals from the surface of water (Quetel et al., 2010) thus, $\mathrm{TiO}_{2}$ have wide applications in environmental remediation.

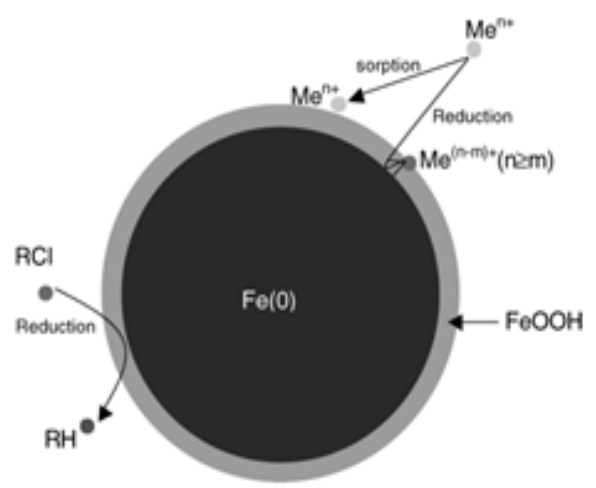

Fig 3 Zero valent Iron nanoparticles (Source: Li et al., 2006)

Zero-Valent Iron (ZVI):Among numerous nanoparticles evaluated for the purpose of environmental remediation, zero valen iron (ZVI) nanoparticles gained momentum in the recent past, and were reported to be one of the most abundant element on earth (Deng et al., 2000). They have been thoroughly studied due to their great reduction potential towards chlorinated contaminants, and have higher sorption capacity and reaction rates compare to bulk particles approximately 25-30 times faster (Mueller and Nowack, 2010). They remediate various toxics contaminants in groundwater, soils, sediments and aquifers (Cundy et al., 2008) like chromate, nitrate, selenate, perchlorate and arsenate (Cao et al., 2005; Nowack, 2008), pesticides, fertilizers and dyes in the soil (Zhang, 2003), Cr (VI) in contaminated water and soil (Medina-Pérez et al., 2019), polycyclic aromatic hydrocarbons (Chang et al., 2007), As (III) Rizwan et al., 2014), Cd and $\mathrm{Pb}$ from polluted soils (Helal et al., 2016) and polychlorinated biphenyls (Varanasi et al., 2007).

ZVI act as effective redox media compared to their bulk counterpart for the detoxification of organic and inorganic pollutants from aqueous environments (Savage and Diallo, 2005), hydrocarbon compounds (Cheng and $\mathrm{Wu}, 2001$; He and Zhao, 2005; Wei et al., 2006 and Zhu et al., 2006), their mechanism of action include, the ion act as reducing agent by donating electrons to the contaminants, thereby reducing them to a less toxic substances (Chuang et al., 1995; Mueller and Nowack, 2010) following this, the insoluble substances would then be precipitated (Helal et al., 2016). Mueller and Nowack, 2010 reported that ZVI nanoparticles remediate various forms of organic pollutants in the soil and groundwater as shown in figure 2. This graphical representation shows that ZVI nanoparticles can be injected into well 1 to form a reactive barrier between contaminated and treated ground water, in well 2 mobile nZVI are injected to form a plume, while the incorporation of nanoparticles in to the top soil degrade the pollutants/contaminants as shown in well 3 .

Dendrimers: These include nanomaterials made usually from organic matter, excluding carbon-based or inorganic-based nanomaterials. They are nanosized polymers consisting of branched units and their interior cavities can be used for drug delivery (NRP, 2017). The surface of a dendrimer has numerous chain ends, which can be adapted to perform specific chemical functions, this property makes it useful as catalysts (Gangadhara, et al., 2012).

Dendrimers in nano remediation: Dendrimers are highly structured macromolecules composed of a central core connected to two or more repetitive branching units (Triano et al., 2015), they are characterized by their sphere-like bifurcated, threedimensional structure (Frechet et al., 2001) and are mono disperse polymers with specific size, solubility, porosity, high degree of molecular uniformity and highly functional terminal groups on their surface (Newkome et al., 2006; wang et al., 2008).

Dendrimers were reported to be used in remediating environmental pollutions (Savage and Diallo, 2005; Triano, 2015; Pawlaczyk et al., 2018; Fernanda et al., 2018) like $\mathrm{Pb}(\mathrm{IV})$ from polluted soil (Xu and Zhao 2006), organic compounds (Diallo et al., 1999), manganese, nitrate, iron, arsenic, heavy metals, $\mathrm{CO}$, $\mathrm{SO} 2$, aliphatic and aromatic hydrocarbons, pharmaceuticals, bacteria, parasites and viruses, etc. (Guerra et al., 2018). PAMAM dendrimers remediate soil and water contaminated with metal ions such as $\mathrm{Cu}^{+}(\mathrm{Xu}$ and Zhao, 2005; Guerra et al., 2018).

Composite-based nanomaterials: These are materials that combine nanoparticles with other nanoparticles or with other materials. They are composite in which at least one of the phases shows dimensions in the nanometers ranging between 1 to $100 \mathrm{~nm}$ (Cônsoli et al., 2019). Nano-composite may be polymer based or non-polymer based nano materials (Pandya, 2015), the incorporation of nanomaterials into composites enhances mechanical, thermal and barrier properties of a material (NRP, 2017). The improvements in these properties have resulted into an interest in nanocomposite been used in various industrial applications as found in environmental cleanup. 


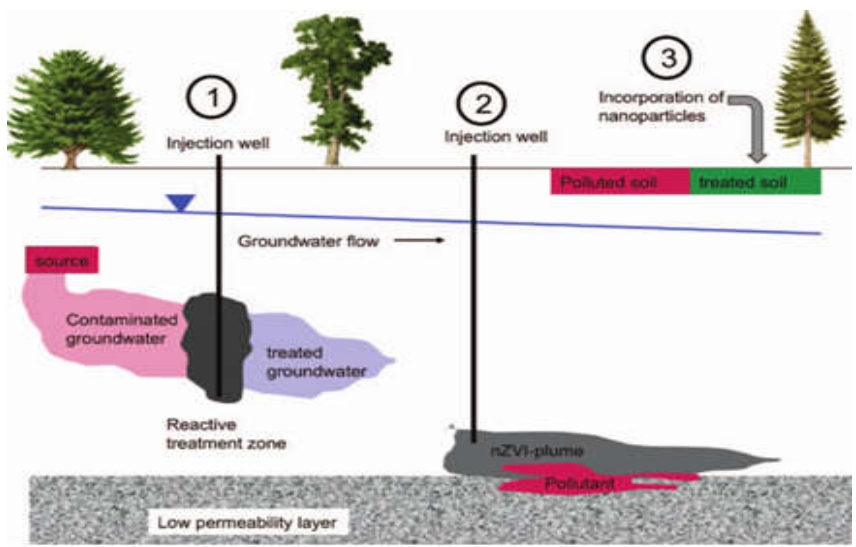

Fig 4 In situ technologies used to treat polluted ground water and Soils: (Source: Mueller and Nowack, 2010)

Table 1: A brief summary of application of nanotechnology in soil and water remediation

\begin{tabular}{|c|c|c|c|}
\hline S/No & Types of nanoparticles & Type of pollutants remediated & References \\
\hline \multirow[t]{7}{*}{1} & Carbon-based & organic and inorganic pollutants & (Jin et al., 2007). \\
\hline & nanomaterials & Fluoride from drinking water & (Mansoori et al., 2008) \\
\hline & Carbon Nanotubes (CNTs) & $\begin{array}{l}\text { Polychlorinated biphenyls, polycyclic } \\
\text { aromatic hydrocarbons }\end{array}$ & (Pan and Xing, 2010) \\
\hline & MWCNTs & Microorganisms, heavy metals & $\begin{array}{l}\text { (Raj Kumar and Gopinath, } \\
\text { 2017) }\end{array}$ \\
\hline & & heavy metals in soils & (Correia, et al., 2019), \\
\hline & SWCNTs & Microorganisms & $\begin{array}{l}\text { (Raj Kumar and Gopinath, } \\
\text { 2017) }\end{array}$ \\
\hline & & $\begin{array}{l}\text { Polychlorinated biphenyls (PCBs) (Hua et } \\
\text { al., 2017) }\end{array}$ & (Hua et al., 2017) \\
\hline \multirow[t]{3}{*}{2} & $\begin{array}{l}\text { Inorganic-based } \\
\text { nanomaterials }\end{array}$ & $\begin{array}{l}\text { chlorinated alkanes, benzenes, dioxins and } \\
\text { furans, polychlorinated biphenyls, } \mathrm{Cr} \text { (VI), } \\
\mathrm{Ag}(\mathrm{I}) \text { and } \mathrm{Pt}(\mathrm{II})\end{array}$ & (Savage and Diallo, 2005) \\
\hline & $\mathrm{TiO}_{2}$ Nanoparticles & $\begin{array}{l}\text { Microorganisms } \\
\text { pesticides; dyes; toxic compounds from the } \\
\text { waste water }\end{array}$ & $\begin{array}{l}\text { (Chatterjee et al., 2016). } \\
\text { (Meghmala et al., 2019) }\end{array}$ \\
\hline & & Heavy metals & (Quetel et al., 2010) \\
\hline \multirow[t]{4}{*}{3} & $\begin{array}{l}\text { Organic-based } \\
\text { nanomaterials }\end{array}$ & $\mathrm{Cu} 2^{+}$from polluted water and soil & $\begin{array}{l}\text { (Xu and Zhao, 2005; Guerra et } \\
\text { al., 2018) }\end{array}$ \\
\hline & Dendrimers & $\begin{array}{l}\mathrm{Pb} \text { (IV) from polluted soil } \\
\text { Manganese, nitrate, iron, arsenic, } \mathrm{CO}, \mathrm{SO} 2, \\
\text { aliphatic and aromatic hydrocarbons, } \\
\text { pharmaceuticals, bacteria, parasites and } \\
\text { viruses, etc. }\end{array}$ & $\begin{array}{l}\text { (Xu and Zhao 2006), } \\
\text { (Guerra } \text { et al., 2018). }\end{array}$ \\
\hline & & organic compounds & (Diallo et al., 1999), \\
\hline & & $\begin{array}{l}\text { ions, gaseous molecules, low molecular } \\
\text { weight organic compounds }\end{array}$ & $\begin{array}{l}\text { (Zimmerman and Lawless } \\
\text { 2001: Triano et al. 2015) }\end{array}$ \\
\hline \multirow[t]{4}{*}{4} & $\begin{array}{l}\text { Composite based } \\
\text { nanoparticles } \\
\text { carbon nanotubes }+\mathrm{ZnO} \\
\text { nanoparticles }\end{array}$ & Congo red dye from aqueous environments & $\begin{array}{l}\text { (Arabi et al., 2019; Khare et } \\
\text { al., 2019), }\end{array}$ \\
\hline & $\begin{array}{l}\text { Polymeric } \mathrm{CNT}+ \\
\text { Calixarenes and } \\
\text { thiacalixarenes }\end{array}$ & $\mathrm{Cd}^{2+}, \mathrm{Pb}_{2}{ }^{+}$and $\mathrm{P}$ - nitrophenol from water. & (Rizwan et al., 2014) \\
\hline & $\begin{array}{l}\text { Ceramic filters+ Poly } \\
\text { (amidoamine) and poly } \\
\text { (ethyleneimine) } \\
\text { dendrimers }\end{array}$ & $\begin{array}{l}\text { Pesticides and polycyclic aromatic } \\
\text { hydrocarbons from water }\end{array}$ & (Arkas et al. 2006), \\
\hline & nZVI+ noble metals & Organic chlorine and hydrogen & (Karn et al., 2009) \\
\hline
\end{tabular}

Composites based nanomaterials can be used to develop various and efficient sensors to detect very low concentrations of chemical compounds in a polluted environments, for example, carbon nanotubes loaded with $\mathrm{ZnO}$ nanoparticles (Composite) can be used to reduce Congo red dye from an aqueous environment (Arabi et al., 2019; Khare et al., 2019), Polymeric CNT incorporated with calixarenes and thiacalixarenes remediate inorganic pollutants such as $\mathrm{Cd}^{2+}$ and $\mathrm{Pb}^{2+}$ and organic ones such as $\mathrm{P}$-nitrophenol from water (Rizwan et al., 2014). Ceramic filters when impregnated with Poly (amidoamine) PAMAM and 
poly (ethyleneimine) dendrimers remediate pollutions such as pesticides and or polycyclic aromatic hydrocarbons from water (Arkas et al., 2006), nZVI can be combined with some noble metals to catalyze dechlorination and hydrogenation reactions with contaminants Karn et al., 2009.

The downside of nanoparticles: It is being realized that nanoparticles are being released into the environment (Wilson, 2018), these nanoparticles may get into the environments through a varieties of known and unknown sources (APHL, 2015). Toxicologist geared up to develop an approach that understand how nanoparticles disperse into the environments and their potential toxicity due to the way they behave (Wilson, 2018), Research has shown that nanoparticles when inhaled, may interact with biological system due to their smallness in size, solubility and large surface area (USEPA, 2017), this may end up binding to proteins in the blood and as such stimulate or sometime suppresses immune responses (Dobrovolskaia and McNeil, 2007). Due to negative impact imposed by nanoparticles, Mueller and Nowack, 2010 reported that most of the nanoparticles require verification of their efficacy and safety in the field as they have been successfully demonstrated in the laboratory scale, this might probably be the reason why few nanotechnological applications for environmental cleanup have been commercialized for now. Many risks associated with nanoparticles are not known at this time, but as more is learned about their transformational behaviour, the number of possible hazardous may escalate over time.

Conclusion: Nanotechnology offers an effective alternative approaches to an existing remediation in environmental pollutions, and the superior performance is due to the novel properties of the nanoparticles. This work put together the most recent techniques applied in remediating soil and water pollution. These techniques are considered to be most efficient and cost effective so far. Organic, Inorganic, carbon-based and nano-composite nanomaterial are among the different types of nano-materials that can be successfully employed for a variety of applications in environmental remediation.

\section{REFERENCES}

Adesina, AA (2004). Industrial exploitation of photocatalysis: progress, perspectives and prospects. Catalysis Surveys from Asia 8 (4): 265-273

Arabi, S; Lalehloo, R S; Olyai, M; Ali, G; Sadegh, H (2019). Removal of congo red azo dye from aqueous solution by $\mathrm{ZnO}$ nanoparticles loaded on multiwall carbon nanotubes. Physica E: Low-Dimensional Systems and Nanostructures. 106: 150-155
Arkas, M; Allabashi, R; Tsiourvas, D; Mattausch, E M; Perfler, R (2006) Organic/inorganic hybrid filters based on dendritic and cyclodextrin "nanosponges" for the removal of organic pollutants from water. Environ Sci Technol 40:2771-2777

Association of Public Health Laboratories (APHL), (2015). Nanotechnology and Environmental Health Laboratories: White Paper

Bottero, J Y; Rose, J; Wiesner, M R (2006) Nanotechnologies: tools for sustainability in a new wave of water treatment processes. Integrated Environmental Assessment and Management, 2 (4):391-395

Cao, J; Elliott, D; Zhang, W X (2005). Perchlorate reduction by nanoscale iron particles. J Nanopart Res 7, 499506

Chang, M C; Shu, H Y; Hsieh, W P; Wang, M C (2007). Remediation of soil contaminated with pyrene using ground nanoscale zero-valent iron. Journal of the Air \& Waste Management Association 57: 221-227

Chatterjee, N; Yang, J; Atluri, R; Lee, W; Hong, J; Choi, J (2016). Amorphous silica nanopaticle-induced perturbation of cholesterol homeostasis as a function of surface area highlights safe-bydesign implementation: an integrated multi-OMICS analysis. RSC Adv 6:68606-68614

Chen, H; Liuyang, Z; Matthew, B; Hong, N; Jinbao, C; Xianqiao, W. (2015) Molecular dynamics study of a CNT-buckyball-enabled energy absorption system. Chem Phys. 17:17311-21

Chen, J P; Lim, L L (2002). Key factors in chemical reproduction by hydrazine for recovery of precious metals. Chemosphere 49:363-370

Cheng, S. F; Wu, S C (2001). "Feasibility of using metals to remediate water containing TCE," Chemosphere, 43 (8): $1023-1028$

Chibueze, A. C; Blaise, C. C; Chijioke, O. G (2016). Bioremediation techniques-classification based on site of application: principles, advantages, limitations and prospects. World J Microbiol Biotechnol 32:180 DOI 10.1007/s11274-016-2137-x

Chuang, F. W; Larson, R. A; Wessman, M. S. (1995). Zero valent Iron-Promoted Dechlorination of Polychlorinated Biphenyls. Environmental Science \& Technology, 29 (9): 2460-2463

Cônsoli S D; da Silva B T T; Molina G D; dos Santos G N A; Müller G L; Cocchieri B E (2019). Electromagnetic Characterization of Recyclable Polymer Nanofibers Based on PSU/Carbonyl Iron. Tech Science Press. JRM 7(3): 280-287 
Correia, A A S; Matos; M.P.S.R; Rasteiro, M.G.B.V (2019). Immobilization of heavy metals in contaminated soils with carbon nanotubes. Proceedings of the XVII ECSMGE doi: 10.32075/17ECSMGE-2019-0185.

Cortes, P; Deng, S; Smith, G B (2009). The adsorption properties of bacillus atrophaeus spores on single wall carbon nanotubes. Journal of Sensors. DOI $10.1155 / 2009 / 131628$

Cundy, A. B; Hopkinson, L; Whitby, R. L. D. (2008). Use of iron-based technologies in contaminated land and groundwater remediation: A review. Sci. Total Environ. 400 42-51

Deng, N; Luo, F; Wu, F; Xiao, M; Wum, X (2000). Discoloration of aqueous reactive dye solutions in the $\mathrm{UV} / \mathrm{Fe} 0$ system. Water Research, 34 (8): 2408-2411

Diallo, M S; Balogh, L; Shafagati, A; Johnson, J H; Goddard, W A; Tomalia, D A (1999). Poly (amidoamine) dendrimers: A new class of high capacity chelating agents for $\mathrm{Cu}$ (II) ions. Environ Sci Technol 22:820-824

Diallo, M. S; Christie, S; Swaminathan, P; Johnson, J H; Goddard, W A. (2005). Dendrimer enhanced ultrafiltration. Recovery of $\mathrm{Cu}$ (II) from aqueous solutions using PAMAM dendrimers with ethylene diamine core and terminal NH2 groups. Environ. Sci. Technol 39, 1366-1377

Dobrovolskaia, M A; McNeil, S E (2007). "Immunological Properties of Engineered Nanomaterials." Nature Nanotechnology. 2; 469 - 478

Durán, N (2008). Use of Nanoparticles in Soil-Water Bioremediation Processes. 5th International Symposium ISMOM. November 24th $-28^{\text {th }}$. Pucón, Chile

Fernanda, D G; Mohamed, F A; Daniel, C W; Alexis, F (2018). Nanotechnology for Environmental Remediation: Materials and Applications. Review. Molecules. 23, 1760

Firozjaee, T T; Mehrdadi, N; Baghdadi, M; Bidhendi, G N (2017). The removal of diazinon from aqueous solution by chitosan/carbon nanotube adsorbent. Desalin. Water Treat. 79: 291-300

Frechet, J M J; Tomalia, D A (2001). Dendrimers and other Dendritic Polymers. John Wiley \& Sons Ltd

Gangadhara, G; Maheshwarib, U; Guptac, S (2012). Application of Nanomaterials for the Removal of Pollutants from Effluent Streams. Nanoscience \& Nanotechnology Asia (2): 140-150

Gao, Z; Bandosz, T J; Zhao, Z; Han, M; Qiu, J (2009) Investigation of factors affecting adsorption of transition metals on oxidized carbon nanotubes. $J$. Hazardous Materials, 167, No. 1-3, 357

Guerra, F D; Attia, M F; Whitehead, D C; Alexis, F (2018). Nanotechnology for Environmental Remediation: Materials and Applications. Review. Molecules. 23, 1760

He, F; D. Zhao, (2005). "Preparation and characterization of a new class of starch-stabilized bimetallic nanoparticles for degradation of chlorinated hydrocarbons in water," Environmental Science and Technology 39 (9): 3314-3320

Helal, M I D; Khater, H. A; Marzoog, A. A (2016). Application of Nanotechnology in Remediation of Heavy Metals Polluted Soils. Journal of Arid Land Studies 26 (3): 129-137

Hochella, M F Jr; Madden A. S (2005). Earth's nanocompartment for toxic metals. Elements 1: 199-203

Hua, S; Gong, Ji; MingZeng, G; Yao, F; Guo, M; MingOu, $\mathrm{X}$; (2017). Mediation of organochlorine pesticides contaminated lake sediment using activated carbon and carbon nano tubes. Chemosphere 177 65-76.

Isa, B; Adam, H B; Usman, Y M; Abdulrahaman, F (2019). Potentials of Nanoparticles for Soil and Water Remediation (A Review). Int J Info Eng \& Techn 10 (3): 19-28.

Jeevanandam, J; Barhoum, A; Chan, Y S; Dufresne, A; Danquah, M K (2018). Review on nanoparticles and nanostructured materials:History, sources, toxicity and regulations. Beilstein Journal of nanotechnology 9: 1050-1074. doi:10.3762/bjnano.9.98.

Jin, j; Li, R; Wang, H. Chen, H; Liang, K; Ma, J. (2007). Magnetic $\mathrm{Fe}$ nanoparticle functionalized watersoluble multi-walled carbon nanotubules towards the preparation of sorbent for aromatic compounds removal. Chemical Communications, 4 386-388

Josko, I; Oleszczuk, P; Pranagal, J; Lehmann, J; Xing, B; Cornelissen, G (2013). Effect of biochars, active ated carbon and multi walled carbon nanotubes on phytotoxicity of sediment contaminated by inorganic and organic pollutants. Ecol. Eng. 60 (11), 50 E 59

Kabra, K; Chaudhary, R; Sawhney, R L (2004). Treatment of hazardous organic and inorganic compounds through aqueous phase photocatalysis: A review. Indus and Eng Chem Resh 43 (24): 7683-7696

Karn, B; Kuiken, T; Otto, M (2009). Nanotechnology and in Situ Remediation: A Review of the Benefits and Potential Risks. Environmental Health Perspectives 117 (12): 1823-1831

Khare, P; Kumar, P R; Shankar, R (2019). Carbon Nanotubes (CNTs) Recent Developments in 
Nanocarbon-Polymer Composites for Environmental and Energy Applications. Intechopen. 1-18

Khin, M M; Sreekumaran, A; Nair, A S; Babu, V J; Murugan, R; Ramakrishna, S (2012) A review on nanomaterials for environmental remediation. Energy \& Environmental Science. 5: 8075-8109

Li, Q; Mahendra, S; Lyon, D Y; Brunet, L; Liga, M V; Li, D; Alvarez, P J J (2008). Antimicrobial nanomaterials for water disinfection and microbial control: Potential applications and implications. Water Res. 42, 45914602

Li, X; Daniel, W E; Zhang, W (2006). Zero-Valent Iron Nanoparticles for Abatement of Environmental Pollutants: Materials and Engineering Aspects. Critical Reviews in Solid State and Materials Sciences, 31:111-122

Machado, S; Pinto, S L; Grosso, J P; Nouws, H P A; Albergaria, J T; Delerue-Matos, C (2013). Green production of zero-valent iron nanoparticles using tree leaf extracts. Sci. total environ. 445, 1

Mamadou, S D; Savage, N (2005). Nanoparticles and water quality. J. Nano. Res., 7,325-330

Mansoori G.A., Rohani Bastami T. Ahmadpour A.Z, Eshaghi (2008). Environmental application of Nanotechnology. Annual Review of Nano Research, 2 (2)

Medina-Pérez, G; Fernández-Luqueño, F; Vazquez-Nuñez, E; López-Valdez, F; Prieto-Mendez, J; MadariagaNavarrete, A Miranda-Arámbula, M. (2019). Remediating Polluted Soils Using Nanotechnologies: Environmental Benefits and Risks. Pol. J. Environ. Stud. 28 (3): 1013-1030

Meghmala, S W; Aparna, B G; Javed, A M; Neha, N P; Neelu, N N (2019). Studies on the titanium dioxide nanoparticles: biosynthesis, applications and remediation Review Paper. SN Applied Sciences 1:310 | https://doi.org/10.1007/s42452-019-0337-3

Mostafavi, S T; Mehrnia, M R Rashidi, A M (2009). Preparation of nano filter from carbon nanotubes for application in virus removal from water. Desalination 238, 1-3 271-280

Mueller, N. C Nowack, B (2010). Nanoparticles for Remediation: Solving Big Problems with Little Particles. Elements, 6: 395-400

National Research Programme (NRP) 64 (2017). Opportunities and risks of nanomaterials. Engineered Nanomaterials: Impact \& Safety Aspects. Swiss National Science Foundation

Neely, W B; Branson, D R; Blau, G E (1974) PartitionCoefficient to Measure Bioconcentration Potential of
Organic Chemicals in Fish. Environmental Science \& Technology 8 (13): 1113-1115

Newkome, G R; Kotta, K K; Moorefield, C N (2006). Design, synthesis and characterization of conifersshaped Dendrimers architectures. Chem. Eur. J. 12 (14): 3726

Niu, H; Cai, Y (2012). Adsorption and concentration of organic contaminants by carbon nanotubes from environmental samples. In Advances in Nanotechnology and the Environment, J. Kim, Ed., pp. 79-136, Pan Stanford Publishing, Singapore.

Nkereuwem, M. E., Edem, I D and Fagbola, O (2010). Bioremediation of oil-polluted soils with organomineral fertilizer (OMF) and Mexican Sunflower (Tithonia diversifolia). Nigerian Journal of Agriculture, Food and Environment. 6 (1\&2):13-20.

Nnaji, J C (2017). Anomaterials for remediation of petroleum contaminated soil and water. Umudike Journal of Engineering and Technology (UJET), 3 (2): $23-29$.

Nowack, B (2008) Pollution prevention and treatment using nanotechnology. In: Krug $\mathrm{H}$ (ed) Nanotechnology. Wiley-VCS Verlag GmbH \& Co, Weinheim, pp 1-15.

Obare, S O; Meyer, G. J (2004). "Nanostructured materials for environmental remediation of organic contaminants in water," Journal of Environmental Science and Health Part A. 39 (10): 2549-2582.

Olyaie, E; Banejad, H. (2012). Soil Properties and Modeling. Recent nanotechnology applied for soil and water remediation: A critical review. Available at https://www. researchgate.net/publication/259266994.

Pan, B; Xing, B (2010). Manufactured nanoparticles and their sorption of organic chemicals, Adv. Agronomy, 108, 137-181.

Pandey, S; Kumari, M; Singh, S P; Bhattacharya, A; Mishra, S; Chauhan, P S; Mishra, A (2015). Bioremediation via Nanoparticles: An Innovative Microbial Approach. DOI: 10.4018/978-1-4666-8682-3.ch019.

Pandya, S (2015). Nanocomposites and its applicationReview. DOI: 10.13140/RG.2.1.2798.9840

Pawlaczyk, M; Kurczewska, J Schroeder, G (2018).Nanomaterials Modification by Dendrimers. A Review. World Journal of Research and Review (WJRR). 6 (5): 14-30.

Quetel, C, Vassileva, E; Petrov, I; Chakarova, K; Hadjiivanov, K (2010) First results on Fe solid-phase extraction from coastal seawater using anatase $\mathrm{TiO} 2$ nano particles. Anal Bioanal Chem 396:2349-2361. 
Rafique, I; Kausar, A; Anwar, Z; Muhammad, B (2016) Exploration of Epoxy Resins, Hardening Systems, and Epoxy/Carbon Nanotube Composite Designed for High Performance Materials: A Review, PolymerPlastics Technology and Engineering, 55 (3): 312333.

Raj Kumar, S; Gopinath, P (2016). Nano-Bioremediation Applications of Nanotechnology for Bioremediation.27-48

DOI: 10.1201/9781315374536-3.

Reddy, K R; Adams, J A (2010). Sustainable Remediation of Contaminated Sites. Momentum Press, New York, NY.

Rickerby, D; Morrison, M (2007). Report from the Workshop on Nanotechnologies for Environmental Remediation, JRC Ispra. Online www. nanowerk.com/ nanotechnology/reports/reportpdf/report 101.

Rizwan, M D; Singh, M; Mitra, C K; Morve, R K (2014). Ecofriendly Application of Nanomaterials: Nano bioremediation. Journal of Nanoparticles. http://dx.doi.org/10.1155/2014/431787.

Savage, N; Diallo, M S (2005). Nanomaterials and water purification: Opportunities and challenges. Journal of Nanoparticle Research. 7: 331-342.

Thai, O, Y; Ahmad A; Hussein, S Zein, S; Huat, S T (2010). A review on carbon nanotubes in an environmental protection and Green engineering perspective. Braz J chem eng 27 (2): 227-242.

Triano, R M; Paccagnini, M L; Balija, A M (2015). Effect of dendrimeric composition on the removal of pyrene from water. SpringerPlus 4:511. DOI 10.1186/s40064-015-1295-x

Tripathi, S; Sanjeevi, R; Anuradha, J; Singh C. D; Ashok, K R (2018). Nano-bioremediation: Nanotechnology and bioremediation. IGI Global. 202-219 DOI:10.4018/978-1-5225-4162-2.ch012.

USEPA, (2007). Nanotechnology White Paper.US Environmental Protection Agency Report EPA 100/B07/001 EPA Washington DC.

USEPA, (2011). Nanotechnology: Applications for Environmental Remediation CLU-IN Technology Focus Area Fact Sheet. CLU-IN.

USEPA, (2017). Technical Fact Sheet - nanomaterials. EPA 505-F-17-002 pp 1-9

Varanasi, P; Fullana, A; Sidhu, S (2007). Remediation of PCB contaminated soils using iron nano-particles. Chemosphere 66: 1031-1038.
Wang, P; Moorefield, C N; Jeong, K U; ,Hwang, S H; Li, S; Cheng, S Z D; George, R; Newkome, G R (2008). Adv. Mater. 201381.

Watlington, K (2005). United State Environmental Protection Agency,.www.epa.gov www.clu-in.org.

Wei, J; Xu, X; Liu, Y; Wang, D (2006). Catalytic hydrodechlorination of 2, 4-dichlorophenol over nanoscale $\mathrm{Pd} / \mathrm{Fe}$ : reaction pathway and some experimental parameters. Water Research 40 (2): 348-354.

WHO, (2013). Cancer prevention. World Health Organization, Washington, DC, USA.

Wilson, N (2018). Nanoparticles: Environmental Problems or Problem Solvers? BioScience 68 (4): 241.

Xu, Y; Zhao, D (2006). Removal of lead from contaminated soils using poly (amidoamine) dendrimers. Ind Eng Chem Res 45:1758-1765

$\mathrm{Xu}$, Y; Zhao, D. (2005). Removal of copper from contaminated soil by use of poly (amidoamine) Dendrimers. Environ. Sci. Technol. 39 (7): 23692375.

Yadav, K K; Singh, J K; Gupta1, N; Kumar, V (2017). A Review of Nanobioremediation Technologies for Environmental Cleanup: A Novel Biological Approach. J. Mat Env Sci (JMES) 8 (2): 740-757.

Yu, J G; Zhao, X H; Yang, H; Chen, X H; Yang, Q; Yu, L Y; Jiang, J H; Chen, X Q (2014). Aqueous adsorption and removal of organic contaminants by carbon nanotubes. Sci. Total Environ, 482: 241-251.

Yunus, I S; Harwin, Kurniawan, A; Adityawarman, D; Indarto, A (2012) Nanotechnologies in water and air pollution treatment, Environmental Technology Reviews, 1:1 136-148, DOI:10.1080/21622515.2012.733966.

Zhang, W (2003) Nanoscale iron particles for environmental remediation: An overview. Journal of Nanoparticle Research 5: 323-332.

Zhu, B. W; Lim, T T; Feng, J (2006). "Reductive dechlorination of 1, 2, 4-trichlorobenzene with palladized nanoscale $\mathrm{Fe} 0$ particles supported on chitosan and silica," Chemosphere, 65 (7): 1137 1145 .

Zimmerman, S C; Lawless, L J (2001). Supramolecular chemistry of dendrimers. Top Curr Chem 217:95120 . 